\title{
Aplicação da Metodologia de Avaliação do Ciclo de Vida Energético a uma Residência em Belém-PA
}

Application of the Energy Life Cycle Assessment Methodology to a Residence in Belém-PA

Aplicación de la Metodología de Evaluación del Ciclo de Vida de la Energía a una Residencia en Belém-PA

COSTA, Simone de Fátima Campos ${ }^{1}$ KOS, Darja ${ }^{2}$

1Programa de Pós-Graduação da Faculdade de Arquitetura e Urbanismo, Faculdade de Arquitetura e Urbanismo, Universidade de Brasília, Brasília, Brasil sc.arquitetura@live.com ORCID ID: 0000-0002-1986-2562

2Programa de Pós-Graduação da Faculdade de Arquitetura e Urbanismo, Faculdade de Arquitetura e Urbanismo, Universidade de Brasília, Brasília, Brasil darja.kos@uol.com.br ORCID ID: 0000-0002-1976-4954 


\section{Resumo}

$\mathrm{Na}$ busca por redução dos impactos energéticos associados a todo ciclo de vida da edificação, a avaliação do ciclo de vida energético - ACVE, mostra-se uma ferramenta eficaz. O artigo tem como objetivo aplicar a ferramenta e classificar a disponibilidade dos dados com escopo, "berço ao túmulo", adotando vida útil de 50 anos em uma residência em Belém do Pará. Na metodologia, estudo de caso, foram inventariadas as demandas energéticas, nas fases pré-uso, uso e pós-uso, utilizando dados secundários. O resultado da energia total do ciclo de vida para o cenário existente, foi $62.75 \mathrm{GJ} / \mathrm{m}^{2}$. A energia operacional na etapa de uso, apresentou o maior consumo energético, $69 \%$ em 50 anos, seguida da energia incorporada inicial com $28 \%$. Na classificação dos dados obtidos concluiu-se que, $70 \%$ dos dados são facilmente obtidos, $10 \%$ demandam certo empenho e os $20 \%$ necessitam de estudos abrangentes. Esses últimos estão relacionados a falta de dados da energia incorporada nos materiais e sistemas construtivos, voltados para realidade brasileira e regional. Por fim, a análise dos valores obtidos, deve ser realizada com cautela e de forma híbrida, critério utilizado dependendo da disponibilidade e dificuldade na obtenção dos dados para o cálculo da energia incorporada.

Palavras-Chave: avaliação do ciclo de vida energético, ACVE, residência, Belém do Pará.

\section{Abstract}

In the search for the reduction of energy impacts associated with the life cycle of buildings, ACVE is an effective tool. The article aims to apply the tool and classify the availability of data with scope, "cradle to the grave", adopting a useful life of 50 years in a residence in Belém do Pará. In the methodology, case study, energy demands were inventoried, in the pre-use, use and post-use phases, using secondary data. The total energy consumption result for the existing scenario was $62.75 \mathrm{GL} / \mathrm{m}^{2}$. The operational energy, in the use stage, presented a higher energy consumption of $69 \%$ in 50 years, followed by the initial incorporated energy with $28 \%$. Finally, it was concluded that $70 \%$ of the data are easily obtained, $10 \%$ demand some effort and the $20 \%$ that need comprehensive studies, are related to the lack of data on the energy incorporated in the materials and construction systems, focused on the Brazilian and regional reality. Finally, the analysis of the values obtained must be carried out cautiously and in a hybrid way, a criterion used depending on the availability of obtaining the data for calculating the incorporated energy.

Key-Words: energy life cycle assessment, LCA, residence, city of Belém in Brazil.

\section{Resumen}

En la búsqueda por la reducción de los impactos energéticos asociados al ciclo de vida de la edificación, ACVE, se muestra una herramienta eficaz. El artículo tiene como objetivo aplicar la herramienta y clasificar la disponibilidad de datos con alcance, "de la cuna a la tumba", adoptando una vida útil de 50 años en una residencia en Belém do Pará. La metodología, estudio de caso, inventariando las demandas de energía, en las fases: pre-uso, uso y post-uso, utilizando datos secundarios. El resultado del consumo energético total para el escenario existente, $62.75 \mathrm{GL} / \mathrm{m}^{2}$. La energía operacional, en la etapa de uso, presentó un mayor consumo energético de $69 \%$ en 50 años, seguido de la energía incorporada inicial con $28 \%$. Porfin, concluyó que el $70 \%$ de los datos son de fácil obtención, $10 \%$ demandan algún esfuerzo y $20 \%$ que necesitan estudios integrales, están relacionados con la falta de datos sobre la energía incorporada en los materiales y sistemas constructivos, enfocados a la realidad brasileña y regional.Finalmente, el análisis de los valores obtenidos debe realizarse con cautela y de forma híbrida, criterio utilizado en función de la disponibilidad y dificultad en la obtención de los datos para el cálculo de la energía incorporada.

Palabras clave: evaluación del ciclo de vida energético, residencia, Belém do Pará. 


\section{Introdução}

Nos últimos anos, a discursão acerca do consumo de energia associado a complexa e interdependente relação entre pessoas, clima e edifícios, torna-se recorrente no debate sobre bem estar e conforto dos ocupantes de uma edificação. Para muitos, o grande impacto no consumo de energia nos edifícios está associado apenas à manutenção das condições ambientais adequadas, a operação dos equipamentos e a cocção. Porém, além desses existem outros impactos energéticos não visíveis, associados a todo o ciclo de vida da edificação, importantes na busca da redução dos impactos ambientais por meio da eficiência energética.

A energia tem um papel importante no desenvolvimento dos países, pois está associada ao crescimento econômico e a melhoria de vida das populações. O uso da energia está associado a diversos setores da sociedade, visando o atendimento das necessidades humanas, tais como, ambiente confortável (aquecido ou resfriado), aquisição de produtos materiais e a necessidade de deslocamento (TEODORO, 2017 apud BLOK; NIEWLAAR, 2017). Contudo, os impactos ambientais causados pela forma como a energia é produzida e utilizada refletem a necessidade de ações estratégicas, que possibilitem uso racional de energia.

O setor da construção civil tem papel fundamental para contribuir, de forma consistente, na redução dos impactos ambientais, no atual paradigma de demanda energética. Muitas pesquisas em eficiência energética tornaram-se objetivo de estudo nacional e internacional, com a finalidade de desenvolver estratégias para a utilização racional de energia, uma vez que, o setor da construção civil é responsável por $40 \%$ do consumo de toda energia produzida no mundo (CTE, CRIATIVE, 2015).

Seguindo a tendência mundial o consumo energético, em edificações no Brasil, corresponde por $42,8 \%$ do consumo de energia elétrica (EPE, 2018). Desse consumo, o setor residencial representa $21,5 \%$, o comercial $14,4 \%$ e o público $6,9 \%$ (EPE, 2018). Para reduzir o consumo energético no setor de edificações no Brasil, estratégias de mensuração de eficiência energética foram desenvolvidas. Temos o Programa Brasileiro de Etiquetagem em Edificações (PBE Edifica), que classifica edificações residenciais, comerciais, de serviços e públicas em categorias, que vão de $A$ (mais eficiente) até $E$ (menos eficiente). Desde 2014, a etiquetagem é obrigatória para edificações públicas federais, novas ou que passam pelo processo de retrofit.

No entanto, a quantificação do consumo energético pelo PBE Edifica, está relacionada apenas a fase de uso (energia operacional) da edificação pois, essa energia consumida está diretamente associada em proporcionar conforto aos usuários da edificação (aquecimento, resfriamento, ventilação e iluminação artificial) e para realização de atividades dentro da edificação (cocção, aquecimento de água e uso de aparelhos eletrodomésticos). Para Sartori e Hestnes (2007), a energia operacional representa a maior demanda em todo ciclo de vida de uma edificação. Contudo, diversos autores afirmam que a energia empregada na produção do edifício, chamada de energia embutida ou incorporada, pode representar parcela significativa no ciclo de vida das edificações (MORAGA, et al, 2017, apud HEINONEN et al., 2016; RAMESH; PRAKASH, SHUKLA, 2010; SARTORI; HESTNES, 2007).

Madeira (2019 apud Yokoo e Yokoyama, 2016), menciona que a energia embutida ou incorporada, resultante da construção de edifícios, é responsável por $20 \%$ de toda energia consumida no mundo, sendo que essa porcentagem fica entre 5 e 10\% nos países desenvolvidos e entre 10 e $30 \%$ nos países em desenvolvimento. Dessa maneira, os valores de consumo energético nos setores residencial, comercial e público são superiores aos valores publicados, pois a energia empregada na construção e na manutenção dessas edificações está contabilizada na origem do consumo energético, isto é, no setor da construção civil e transportes. 
Os estudos de ACV, no setor da construção civil, foram iniciados na década de 1990 e, é considerada um indicador de sustentabilidade (SATTLER, 2019). Mas, em razão da sua metodologia de elevada complexidade, versões simplificadas ou recortes vem sendo adotados como forma de facilitar a busca de dados e a interpretação dos resultados. Para a construção civil, os pesquisadores vêm empregando às simplificações de ACV, como a Avaliação do Ciclo de Vida de Emissões de $\mathrm{CO}_{2}\left(\mathrm{ACV} \mathrm{CO}_{2}\right)$, Avaliação do Custo do Ciclo de Vida (ACVC), Avaliação do Ciclo de Vida Modular (ACV-m) e a Avaliação do Ciclo de Vida Energético (ACVE).

A Avaliação do Ciclo de Vida Energético (ACVE) no Brasil, tem sua estrutura metodológica baseada em ACV, com as recomendações da norma NBR ISO 14.040 - Gestão Ambiental - Avaliação do Ciclo de Vida - Princípios e Estrutura (ABNT, 2014a), sendo inventariados apenas os dados de consumos energéticos, diretos e indiretos, tornando a energia um indicador de impacto ambiental. Essa forma simplificada, porém, significativa, permite avaliar também outros impactos ambientais importantes, como a emissão de gases do efeito estufa. Autores como Fay et al. (2000), já defendiam a ACVE como uma proposta, não para substituir a análise ambiental ampla de uma ACV, mas como uma forma de facilitar, preferencialmente, uma tomada de decisão acerca da eficiência energética e dos impactos associados, como a geração de $\mathrm{CO}_{2}$

No Brasil, um dos pioneiros nos estudos em ACVE de edificações é Tavares (2006), trazendo para a realidade brasileira, valores de consumo de energia em todas as etapas do ciclo de vida da edificação. Em sua pesquisa, verificou que $70 \%$ da energia utilizada na manufatura dos principais materiais construtivos brasileiros provém de fontes fósseis não renováveis. Para isso, se faz necessário o entendimento dos fluxos energéticos, a fim de compreender a maneira como se consomem os recursos (TAVARES, 2006).

No estudo de ACVE, é importante a definição do escopo, isto é, a delimitação das fronteiras de estudo, tipos de impactos que serão analisados e unidade funcional. Essa delimitação costuma ser definido pelos termos: "berço ao portão", "portão ao portão", "berço ao túmulo" e "berço ao berço". Caldas, Pedroso e Sposto (2016) definem os termos da seguinte forma:

"Berço ao Portão": o impacto da extração das matérias primas e a manufatura do material;

"Portão ao Portão": etapa que ocorre no interior da indústria;

"Berço ao Túmulo": da extração da matéria prima à destinação final, análise de todos os estágios do ciclo de vida;

"Berço ao Berço": desde a extração das matérias primas até a destinação dos resíduos, quando estes últimos são incorporados à fase inicial de outros processos produtivos, por meio da reciclagem ou reutilização.

Os estudos nacionais englobam principalmente as etapas que vão do "berço ao portão" e do "portão ao portão". Enquanto, nos estudos internacionais, destaca-se o escopo mais completo do "berço ao túmulo". A produção científica no Brasil em ACVE de edificações, ainda ocorre de forma incipiente. Diversas pesquisas utilizam a ACVE como ferramenta, mas estão voltadas a quantificar o consumo energético e/ou emissões de $\mathrm{CO} 2$ em matérias-primas ou sistemas construtivos, com recorte principalmente na etapa do pré-uso. Pesquisas com o escopo mais completo do "berço ao túmulo" no país temos: Tavares (2006), Silva (2012) e Caldas, Pedroso e Sposto (2016).

Embora considerada uma ferramenta estratégica, a ACVE encontra algumas barreiras de aplicação no setor da construção civil, mais especificamente em edificações, em muitos países incluindo o Brasil. Dentre as limitações identificadas no país têm-se: a escassez de especialistas, a falta de incentivos fiscais e públicos, além da baixa adesão de fornecedores de materiais e sistemas, que possuem 
restrições em divulgar informações de seus produtos (MADEIRA 2019, apud EVANGELISTA et al. 2016), a utilização de legislação de outros países (FREITAS; SCHMID; SILVA, 2016), a adaptação a informações desses bancos de dados (SILVA et al, 2016), que limita a realização de inventários locais (PAULSEN; SPOSTO, 2013), como também a grande variabilidade nos resultados, em função da falta de homogeneidade metodológica (PAULSEN e SPOSTO, 2013; TAVARES, 2006).

Mas, apesar das limitações citadas, Carvalho e Silvoso (2017) destacam duas situações relevantes no Brasil: a implantação de políticas governamentais voltadas a sustentabilidade, como a exigência de compras sustentáveis e a instituição do Programa Brasileiro de Avaliação do Ciclo de Vida (PBACV), em 2010. Assim, superar tais barreiras deve ter início com a formação de atribuições, de arquitetos, engenheiros, construtores, desenvolvedores e autoridades públicas, facilitando a expansão da ferramenta ACVE.

Teodoro (2017) menciona que a realização de pesquisas acadêmicas de estudos de casos, proporciona a oportunidade da caracterização do assunto, possibilitando o desenvolvimento de políticas públicas no Brasil. Nesse contexto, pretende-se com esse trabalho contribuir para a caracterização do panorama brasileiro, através da realização de um estudo de caso, para fins acadêmicos, aplicando a metodologia da ACVE a uma edificação unifamiliar.

\section{Objetivos}

A principal motivação deste trabalho é a aplicação da ferramenta de ACVE, em uma residência na região Metropolitana de Belém do Pará, e classificar a disponibilidade de dados necessários para a realização do cálculo.

Para tanto, torna-se necessário concretizar os seguintes objetivos específicos:

a. Promover levantamento dos dados físicos e quantitativos de matérias, equipamentos e sistemas de uma edificação;

b. Calcular a energia consumida nas fases pré-uso, uso e pós-uso;

c. Identificar e classificar os dados em facilmente obtidos, dados que demandam certo empenho e os que demandam estudos abrangentes.

\section{Método}

O presente trabalho tem uma abordagem quantitativa de natureza aplicada, pois a pesquisa considera - levantamento do espaço físico, número de equipamentos e lâmpadas, além de pesquisas bibliográfica e documental, para embasar o objetivo de calcular a energia nas fases de pré-uso, uso e pós-uso, e classificar a disponibilidade de dados necessários para aplicação de ACVE a uma edificação residencial na região metropolitana de Belém do Pará.

O método utilizado foi o estudo de caso que, em virtude da pandemia do COVID-19, para atender as medidas estabelecidas pela Organização Mundial de Saúde (OMS) e Ministério da Saúde (MS), que determinou a quarentena e o distanciamento social, além de outros protocolos. Optou-se por realizar a aplicação da metodologia na residência da autora, com escopo do "berço ao túmulo", adotando vida útil da habitação de 50 anos e unidade funcional em metro quadrado de área construída.

A pesquisa seguiu as recomendações da NBR ISO 14.040 (ABNT, 2014a), sendo inventariado somente as demandas energéticas. Porém, mesmo tendo como base a norma mencionada, ocorrem divergências sobre grande variabilidade nos resultados, em função da falta de homogeneidade metodológica (PAULSEN e SPOSTO, 2013; TAVARES, 2006). Nesse sentido, seguimos os conceitos de Tavares (2006) e Caldas, Pedroso e Sposto (2016) apresentados na tabela 1.

A tabela 1 apresenta as descrições das fases e etapas mais utilizadas do ciclo de vida energético de 
edificações residenciais. Para a realização do ciclo completo de ACVE, são consideradas todas as entradas de energia de uma edificação durante sua vida útil, nas fases: pré-uso, uso e pós-uso.

Tabela 1: Descrição das fases e etapas mais utilizadas do ciclo de vida energético residencial.

\begin{tabular}{|c|c|c|c|c|}
\hline FASE & ETAPAS & SIGLAS & DESCRIÇÃO & ENERGIAS FINAIS \\
\hline \multirow{6}{*}{ Pré-uso } & 1 & \multirow[t]{2}{*}{ EEmat } & $\begin{array}{l}\text { Prospecção, fabricação e transporte de } \\
\text { insumos }\end{array}$ & \multirow{6}{*}{$\begin{array}{c}\text { Energia Incorporada Inicial } \\
\text { EII (MJ) }\end{array}$} \\
\hline & 2 & & Fabricação dos materiais de construção & \\
\hline & 3 & Etr.mat & Transporte dos materiais até a obra & \\
\hline & 4 & Eexe & Energia gasta na execução da obra & \\
\hline & 5 & Edesp & Energia de desperdício & \\
\hline & 6 & Etr.desp & Energia de transporte de desperdício & \\
\hline \multirow{3}{*}{ Uso } & 7 & Eman & Energia de manutenção & \multirow{3}{*}{$\begin{array}{c}\text { Energia Operacional } \\
\text { EO (MJ) }\end{array}$} \\
\hline & 8 & Eequi & $\begin{array}{l}\text { Energia consumida por equipamentos } \\
\text { eletrodomésticos }\end{array}$ & \\
\hline & 9 & Ecocção & Energia para cocção de alimentos & \\
\hline \multirow{2}{*}{ Pós-uso } & 10 & Edem & Energia de equipamentos de demolição & \multirow{2}{*}{$\begin{array}{c}\text { Energia Pós-operacional } \\
\text { EPO (MJ) }\end{array}$} \\
\hline & 11 & Etr.dem & Energia de transporte de demolição & \\
\hline
\end{tabular}

Fonte: Tavares (2006), adaptado pela autora.

Assim, temos que cada fase possui suas etapas correspondentes e que a fase de pré-uso, apresenta maior número de etapas ( 1 a 6). As etapas 1 e 2 estão relacionadas a energia incorporada de cada material $\left(E I M J / \mathrm{m}^{2}\right)$, valores adotados de Tavares (2006). As etapas 3 e 6 relacionadas ao transporte tem fator $0,13 \mathrm{MJ} / \mathrm{Km} / \mathrm{t}$ (TAVARES, 2006). A etapa 4 não foi aplicada no estudo, pois na época da construção a demanda de energia foi considerada nula e na sua ampliação, pouco consumo elétrico, considerado não significativo. A etapa 5 tem o fator de perda para cada material adotados de Agopyan et Al (1998).

$\mathrm{Na}$ fase de uso, para cálculo da energia de manutenção (etapa 7), que está relacionada a substituição dos materiais durante a vida útil da edificação, os valores referentes a vida útil de projeto (VUP), correspondem ao mínimo obrigatório segundo a norma NBR 15.575 - Desempenho de edificações habitacionais (ABNT, 2013 - parte 1). Por sua vez, na etapa 8 energia de equipamentos, foi levantado o quantitativo dos aparelhos elétricos e luminárias com suas respetivas potências, e por meio de uma entrevista informal com os usuários, estipulou-se o tempo de utilização de cada aparelho elétrico e a permanência das lâmpadas acessas, para estimativa da demanda no período de 30 dias e obtenção dos consumos médio mensal e consumo anual em Kw/h. Para a cocção de alimentos foi calculado o consumo de "gás de cozinha", tendo como referência a equivalência $1 \mathrm{~kg}$ GLP pra 13,8 KW/h encontrado no site da Sociedade Fogás Ltda.

Por conseguinte, na fase de pós-uso para o cálculo da energia empregada para a demolição ou desmonte da edificação, foi considerado o fator de energia de demolição de 0,0354 MJ/Kg (TAVARES, 2006). Para o transporte dos resíduos ao descarte final, foi adotado o fator de transporte dos materiais ao canteiro de obra, 0,26 MJ/Km/t (TAVARES, 2006).

Para a classificação dos dados, em facilmente obtidos, que demandam certo empenho e os que demandam estudos abrangentes, foi levado em consideração a adaptação de informações e a falta de dados para a região norte, fato que limita a realização de inventários locais (PAULSEN; SPOSTO, 2013).

\subsection{Descrição da edificação}

Trata-se de uma habitação unifamiliar, localizada na região norte do país em Belém do Pará, no 
Distrito Administrativo de Icoaraci (DAICO), no bairro Ponta Grossa. A implantação da edificação assinalada no círculo verde na Figura 1, está a 50,00 metros do acesso à via pública que se realiza pela Travessa Itaboraí.

Figura 1: Localização de Belém, do DAICO, do bairro Ponta Grossa e edificação.

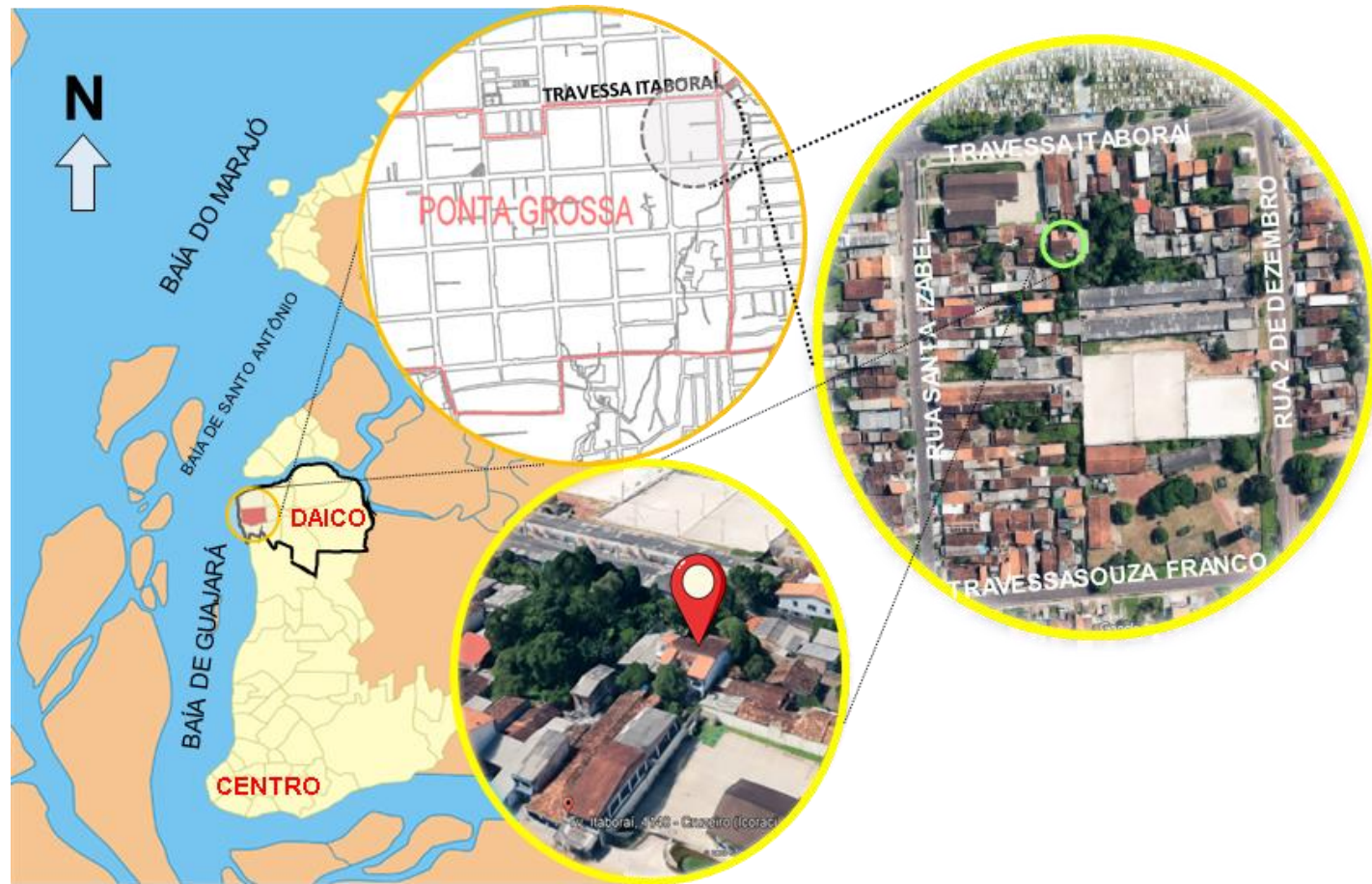

Fonte: Companhia de Desenvolvimento e Administração da Área metropolitana de Belém - CODEM e Google Maps adaptado pela autora, 2020

A edificação, habitada por quatro pessoas, possui área total construída de 225,98 $\mathrm{m}^{2}$, distribuídos em dois pavimentos, foi executada em 1982, após 13 anos passou por uma reforma e ampliação, passando a dois pavimentos (figura 2 e 3 ). A estrutura física da residência é grande, comparada aos padrões de estudo de Tavares (2006), em relação a área.

Figura 2: Fachada principal.

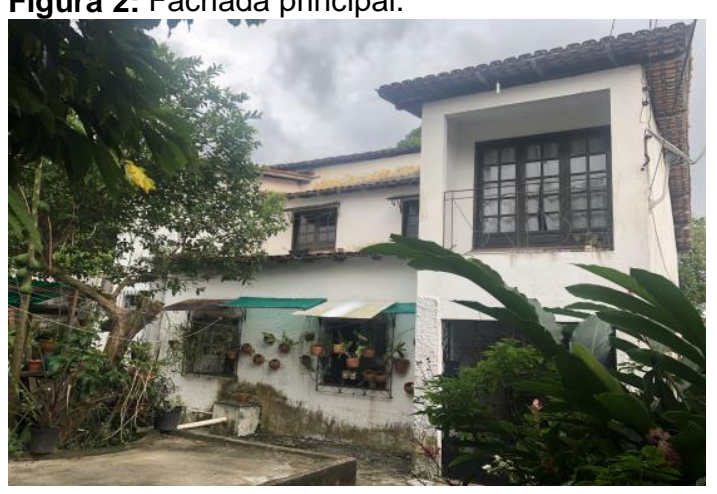

Fonte: Arquivo pessoal, 2020.
Figura 3: Fachada posterior.

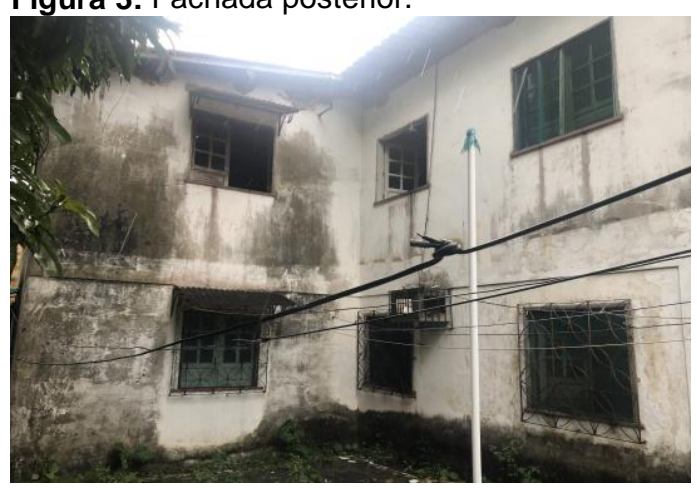

Fonte: Arquivo pessoal, 2020.

A residência foi construída, ampliada e reformada como a grande maioria das edificações do país, sem projetos e acompanhamento de profissional de engenharia e ou arquitetura. Esse fato, estabelece alguns critérios para a quantificação dos materiais inventariados, listados na tabela 3, (estrutura, paredes, cobertura, esquadrias e piso), onde os elementos que compõem esses sistemas foram 
calculados com base em uma composição básica.

A figura 4 apresenta a distribuição dos ambientes no pavimento térreo: pátio, sala de estar com escada de acesso ao $2^{\circ}$ pavimento, sala de jantar, cozinha, três quartos e um banheiro, área de serviço e depósito. E a figura 5 o pavimento superior com sala de TV, home office, sacada, dois quartos, ateliê e banheiro. Na tabela 2 suas respectivas áreas.

Figura 4: Planta baixa pavimento térreo

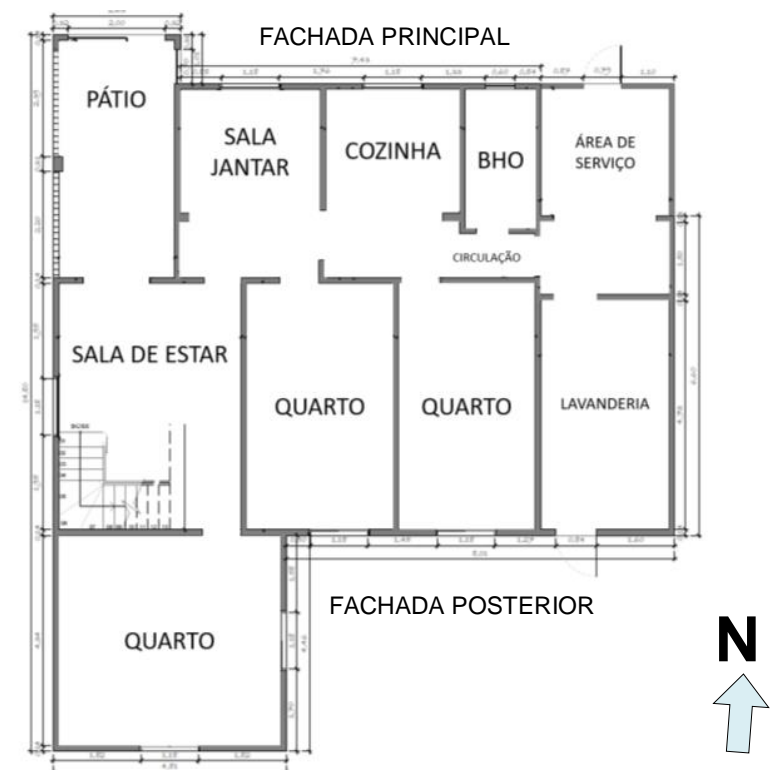

Fonte: Elaboração própria, 2020
Figura 5: Planta baixa pavimento superior

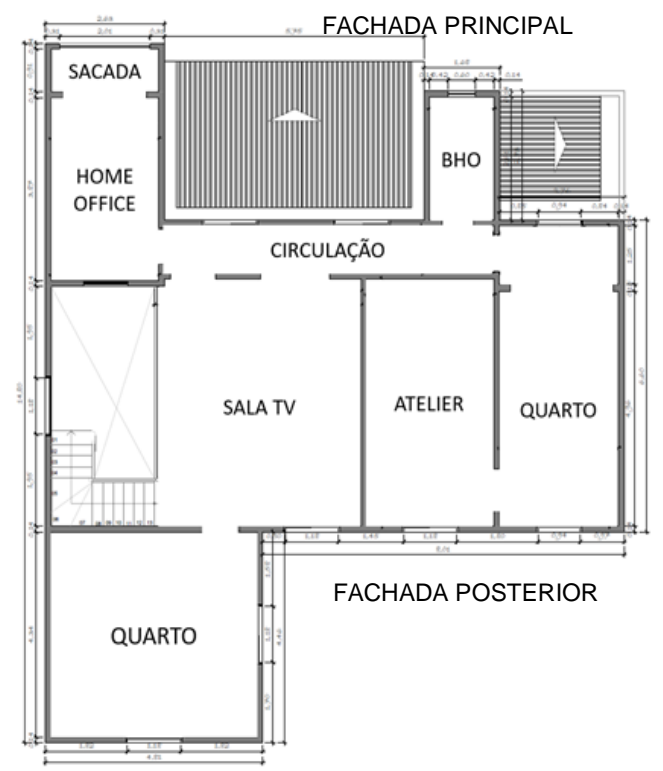

Fonte: Elaboração própria, 2020

Tabela 2: Quadro de áreas da edificação.

\begin{tabular}{l|l|c|l|l|c}
\hline Pavimento & Ambientes & Area m² & Pavimento & Ambientes & Area m² \\
\hline & Pátio & 11.68 & & Sala tv & 23.24 \\
& Sala de estar & 15.93 & & Circulação & 7.31 \\
& Sala de jantar & 11.09 & & Home office & 9.24 \\
& Cozinha & 10.60 & & Sacada & 2.41 \\
Térreo & Banheiro & 4.10 & & Quarto & 19.83 \\
& Circulação & 1.41 & Superior & Quarto & 16.73 \\
& Quarto & 19.83 & & Atelier & 14.82 \\
& Quarto & 15.27 & & Banheiro & 3.75 \\
& Quarto & 14.35 & & & \\
\hline Total pavimento térreo & 11.91 & & & \\
\hline TOTAL GERAL & Área de serviço & 12.48 & & & \\
\hline
\end{tabular}

A tabela 3 resume as características físicas da edificação e apresenta os sistemas e materiais que são utilizados na pesquisa. O sistema construtivo é do tipo convencional em concreto armado. A alvenaria de vedação em blocos cerâmicos, com fundação em blocos de concreto armado, interligados por vigas baldrame, com pilares de concreto armado e laje pré-moldada.

Tabela 3: Características físicas dos materiais e sistemas

\begin{tabular}{c|l|l}
\hline \multicolumn{2}{|c|}{ Edificação } & \\
\hline Sistema & \multicolumn{1}{|c}{ Material } & Descrição \\
\hline Estrutura & Cimento & Concreto armado \\
\hline
\end{tabular}




\begin{tabular}{|c|c|c|}
\hline & Seixo & \\
\hline & Areia & \\
\hline & Aço & \\
\hline \multirow{5}{*}{ Paredes } & Bloco cerâmico & Blocos cerâmicos 06 furos $(9 \times 14 \times 24)$ \\
\hline & Areia & \multirow{2}{*}{ Espessura total $=14 \mathrm{~cm}$ (9 blocos, 2,5 rec. Int. e ext.) } \\
\hline & Cimento & \\
\hline & Tinta Acrílica & \multirow{2}{*}{ Reboco interno e externo, pintura em cor branco } \\
\hline & Tinta PVA látex & \\
\hline \multirow{3}{*}{ Cobertura } & Estrutura madeira & Telhado em estrutura de madeira, \\
\hline & Telha cerâmica & recoberto com telha cerâmica. \\
\hline & Forro PVC & Forro PVC $10 \mathrm{~cm}$ \\
\hline \multirow{2}{*}{ Piso } & Porcelanato & \multirow{2}{*}{$\begin{array}{l}\text { Home office em tábuas de madeira corrida } \\
\text { e demais ambientes em cerâmica esmaltada. }\end{array}$} \\
\hline & Argamassa & \\
\hline \multirow{3}{*}{ Esquadrias } & Madeira & Portas internas e Janelas em madeira e vidro \\
\hline & Alumínio & Porta e balancins do banheiro \\
\hline & Vidro & Uma porta de vidro temperado e os vidros janelas \\
\hline
\end{tabular}

\subsection{Inventário de dados}

Fonte: Elaboração própria, 2020

Para o desenvolvimento do trabalho, alguns dados foram obtidos de forma secundária, da literatura nacional (Tavares, 2006; Agopyan et al, 1998), e ABNT NBR 15.575 (2013a). A tabela 4 apresenta os valores considerados de energia incorporada $\mathrm{EI}(\mathrm{MJ} / \mathrm{Kg}$ ), vida útil de projeto - VUP (anos), fator de reposição $(\mathrm{Fr})$, fator de perda $(\mathrm{Fp})$ e distância calculada via Google Maps para cada material inventariado na pesquisa.

Tabela 4: Características dos materiais consideradas no cálculo da ACVE na pesquisa

\begin{tabular}{|c|c|c|c|c|c|c|c|c|}
\hline \multicolumn{2}{|c|}{ Edificação } & \multirow{2}{*}{$\begin{array}{c}\text { Quantidade } \\
(\mathrm{Kg})\end{array}$} & \multirow{2}{*}{\begin{tabular}{|c|}
$\begin{array}{c}E l^{1} \\
(\mathrm{Mj} / \mathrm{Kg})\end{array}$ \\
\end{tabular}} & \multirow{2}{*}{$\begin{array}{l}\text { VUP }^{2} \\
\text { (anos) } \\
\end{array}$} & \multirow{2}{*}{$\mathrm{Fr}-1$} & \multirow{2}{*}{\begin{tabular}{|c|}
$\mathrm{Fp}^{3}$ \\
$\%$ \\
\end{tabular}} & \multirow{2}{*}{$\begin{array}{c}\text { Transp. } \\
(\mathrm{Km})\end{array}$} & \multirow{2}{*}{ Fábrica / Endereço } \\
\hline Sistema & Material & & & & & & & \\
\hline \multirow{4}{*}{ Estrutura } & Cimento & 9050.00 & 4.20 & 50 & 0.00 & 40 & 207 & $\begin{array}{c}\text { Votorantim } \\
\text { Cimentos, } \\
\text { Primavera-Pa, }\end{array}$ \\
\hline & Seixo & 19545.00 & 0.15 & 50 & 0.00 & 40 & 196 & \multirow{2}{*}{$\begin{array}{l}\text { Seixeira Aurora, } \\
\text { Capitão Poço-Pa, }\end{array}$} \\
\hline & Areia & 29310.00 & 0.05 & 50 & 0.00 & 44 & 196 & \\
\hline & Aço & 3104.80 & 30.00 & 50 & 0.00 & 10 & 557 & $\begin{array}{c}\text { Sinobras, Marabá- } \\
\qquad \mathrm{Pa},\end{array}$ \\
\hline \multirow{5}{*}{ Paredes } & $\begin{array}{l}\text { Bloco } \\
\text { cerâmico }\end{array}$ & 36818.77 & 2.90 & 40 & 0.25 & 15 & 20.2 & $\begin{array}{c}\text { Cerâmica Marituba } \\
\text { LTDA, } \\
\text { Ananindeua-Pa, }\end{array}$ \\
\hline & Areia & 1338.00 & 0.05 & 13 & 2.85 & 44 & 196 & $\begin{array}{l}\text { Seixeira Aurora, } \\
\text { Capitão Poço-Pa, }\end{array}$ \\
\hline & Cimento & 7350.00 & 4.20 & 13 & 2.85 & 40 & 207 & $\begin{array}{c}\text { Votorantim } \\
\text { Cimentos, } \\
\text { Primavera-Pa, }\end{array}$ \\
\hline & $\begin{array}{l}\text { Tinta } \\
\text { Acrílica }\end{array}$ & 109.15 & 61.00 & 8 & 5.25 & 16 & 2042 & \multirow{2}{*}{$\begin{array}{c}\text { Basf S/A- Suvinil, } \\
\text { Jaboatão dos } \\
\text { Guararapes-Pe }\end{array}$} \\
\hline & $\begin{array}{l}\text { Tinta PVA } \\
\text { látex }\end{array}$ & 193.34 & 65.00 & 3 & 15.66 & 16 & 2042 & \\
\hline \multirow{3}{*}{ Cobertura } & $\begin{array}{l}\text { Estrutura } \\
\text { madeira }\end{array}$ & 12230.40 & 0.50 & 30 & 0.67 & 10 & 3.2 & $\begin{array}{c}\text { Promap, } \\
\text { Icoaraci- Belém- } \\
\mathrm{Pa},\end{array}$ \\
\hline & $\begin{array}{l}\text { Telha } \\
\text { cerâmica }\end{array}$ & 9770.08 & 5.40 & 30 & 0.67 & 10 & 148 & $\begin{array}{l}\text { Telha Cerâmica } \\
\text { Forte, } \\
\text { São Miguel do } \\
\text { Guamá-Pa, }\end{array}$ \\
\hline & Forro PVC & 252.00 & 80.00 & 30 & 0.67 & 10 & 9.7 & $\begin{array}{c}\text { Polyperfil forro } \\
\text { PVC, Ananindeua- } \\
\mathrm{Pa},\end{array}$ \\
\hline Piso & Porcelanato & 2925.99 & 13.00 & 13 & 2.85 & 15 & 2052 & $\begin{array}{c}\text { Eliane } \\
\text { Revestimentos, } \\
\text { Camaçari-Ba, }\end{array}$ \\
\hline
\end{tabular}




\begin{tabular}{|c|c|c|c|c|c|c|c|c|}
\hline & Argamassa & 1083.70 & 2.10 & 13 & 2.85 & 18 & 43.5 & $\begin{array}{c}\text { Quartzolit, } \\
\text { Benevides-PA, }\end{array}$ \\
\hline \multirow{3}{*}{ Esquadrias } & Madeira & 534.99 & 7.50 & 20 & 1.50 & 0 & 2.8 & $\begin{array}{l}\text { Mercadão das } \\
\text { portas, } \\
\text { Maracacuera, } \\
\text { Belém-Pa, }\end{array}$ \\
\hline & Alumínio & 95.16 & 210.00 & 30 & 0.67 & 0 & 2882 & \multirow{2}{*}{$\begin{array}{c}\text { Quality } \\
\text { esquadrias, } \\
\text { Bragança Paulista- } \\
\text { SP, }\end{array}$} \\
\hline & Vidro & 91.10 & 18.50 & 30 & 0.67 & 0 & 2882 & \\
\hline
\end{tabular}

NOTA: $\mathrm{EI}=$ Energia incorporada por $\mathrm{Kg}$ do material; VUP = Vida útil de projeto; $\mathrm{Fr}=$ fator de reposição; Fp = Fator de perda Fonte: (1) TAVARES, 2006; (2) ASBEA, ABNT NBR 15575, 2013; (3) AGOPYAN et Al. 1998, (4) Google Maps.

Para o desenvolvimento da pesquisa buscou-se adotar os valores de energia incorporada para os materiais fabricados na região, exceto: piso, tinta e esquadria de alumínio, pois suas fábricas estão fora da região norte. Mas, apesar dos esforços em trazer os valores de energia incorporada para realidade brasileira, ainda é escassa a literatura técnica com estes dados. Portanto, a análise deve ser realizada com cautela e de forma híbrida, que corresponde a um dos 4 tipos de métodos de análise da energia incorporada, que pode ser utilizada dependendo da disponibilidade e dificuldade de obtenção dos dados necessários para o cálculo da energia incorporada (SARTORI 2018, apud TAVARES, 2006).

Diferentemente do restante do país, na região norte, o agregado utilizado na composição do concreto é o seixo, por ser abundante na região. Entretanto, para o seixo, o valor da energia incorporada não foi encontrado, sendo adotado o valor de energia incorporada da brita, adotado de Tavares (2006).

Os valores referentes a vida útil de projeto (VUP), correspondem ao mínimo obrigatório, sugerida pelo guia para arquitetos, desenvolvido pela Associação Brasileira de Escritório de Arquitetura (ASBEA), baseado nos dados da NBR 15575 - parte 1 (ABNT, 2013). O fator de reposição foi calculado pela divisão da vida útil adotada (50 anos) pelo VUP. Não foram considerados a manutenção e o fator de reposição para estrutura e para fundação. $O$ fator de perda das esquadrias adotado foi de $0 \%$, pelo material já chegar pronto na obra.

A energia de transporte, na fase de pré-uso, foi calculada com ajuda do Google Maps, considerando o menor trajeto entre as fábricas e a obra. As fabricas selecionadas seguiram o critério de regionalização, com menor distância até a obra. As fábricas de tinta, piso e alumínio foram selecionadas pela marca do fabricante, optando-se pelas fábricas localizadas mais próximo da região norte. Foi desconsiderada a distância entre as lojas de material de construção e a obra, por se tratar de um percurso curto, com relativamente baixo impacto.

Para o cálculo da energia operacional foram criados 2 cenários, conforme descrição abaixo:

- Cenário 1, C1 (cenário referência - maior consumo): com ar-condicionado split em todos os ambientes de permanência prolongada;

Cenário 2, C2 (cenário existente - base): ausência de ar-condicionado.

Os condicionadores de ar foram selecionados pela planilha (versão 2/7/2020), disponível no site do Instituto Nacional de Metrologia, Qualidade e Tecnologia - IMETRO, com base no Programa Brasileiro de Etiquetagem - PBE, com classificação A. Os equipamentos escolhidos para ar-condicionado resultaram em uma energia de equipamentos de $3.254,42 \mathrm{Kwh} /$ mês para o cenário 1 . Enquanto o cenário 2, existente corresponde a 719,02 Kwh/mês.

$\mathrm{Na}$ fase pós-uso, não foi encontrada em Belém empresa especializada em reciclagem de portas, janelas e outros materiais de obra. Por isso, foi considerada a demolição total da residência, excluindo 
apenas o sistema de fundação, metodologia adotada nas pesquisas de Caldas, Pedroso e Sposto (2016). O entulho gerado é transportado para o aterro sanitário que fica a $28,15 \mathrm{Km}$ de distância. Para se obter o valor da energia incorporada dessa etapa, multiplica-se o fator de transporte $0,26 \mathrm{MJ} / \mathrm{Km} / \mathrm{t}$ (TAVERES, 2006) pela massa total e pela distância percorrida até o aterro sanitário, em seguida soma-se o consumo da energia de demolição.

\section{Resultados}

A partir do levantamento do consumo energético de cada fase, a tabela 5 apresenta os resultados de energia consumida para as fases de pré-uso, uso e pós-uso, para o cenário existente da residência. Exceto a etapa 4 considerada não significativa, já exposto no item 3.

Tabela 5: Descrição das etapas e respectivos consumos do ciclo de vida energético da edificação.

\begin{tabular}{|c|c|c|c|c|c|}
\hline FASE & ETAPAS & SIGLAS & DESCRIÇÃO & $\begin{array}{c}\text { CONSUMO } \\
\text { DE } \\
\text { ENERGIA } \\
\left(\mathrm{G} / \mathrm{m}^{2}\right)\end{array}$ & $\begin{array}{l}\text { TOTAL } \\
\text { FASES } \\
\left(\mathrm{GJ} / \mathrm{m}^{2}\right)\end{array}$ \\
\hline \multirow{6}{*}{ Pré-uso } & 1 & \multirow{2}{*}{ EEmat } & $\begin{array}{l}\text { Prospecção, fabricação e transporte de } \\
\text { insumos }\end{array}$ & \multirow{2}{*}{1.94} & \multirow{6}{*}{17.77} \\
\hline & 2 & & $\begin{array}{l}\text { Fabricação dos materiais de } \\
\text { construção }\end{array}$ & & \\
\hline & 3 & Etr.mat & Transporte dos materiais até a obra & 14.03 & \\
\hline & 4 & Eexe & Energia gasta na execução da obra & - & \\
\hline & 5 & Edesp & Energia de desperdício & 0.40 & \\
\hline & 6 & Etr.desp & Energia de transporte de desperdício & 1.40 & \\
\hline \multirow{3}{*}{ Uso } & 7 & Eman & Energia de manutenção & 17.20 & \multirow{3}{*}{42.98} \\
\hline & 8 & Eequi & $\begin{array}{l}\text { Energia consumida por equipamentos } \\
\text { eletrodomésticos }\end{array}$ & 24.07 & \\
\hline & 9 & Ecoç̧ão & Energia para cocção de alimentos & 1.71 & \\
\hline \multirow{2}{*}{ Pós-uso } & 10 & Edem & Energia de equipamentos demolição & 0.01 & \multirow{2}{*}{2.00} \\
\hline & 11 & Etr.dem & Energia de transporte de demolição & 1.99 & \\
\hline & & Ecve & TOTAL DO CICLO DE VIDA & 62.75 & \\
\hline
\end{tabular}

O valor total do consumo de energia para cenário 2, situação atual, tem o valor de $62.75 \mathrm{GJ} / \mathrm{m}^{2}$. Observa-se um elevado valor na energia de transporte dos materiais (etapa 3), que está associado a distância das fábricas de tinta, piso e alumínio, que ficam na Região Nordeste e Sudeste, respectivamente. Outro destaque, é a energia de manutenção, associada aos valores mínimos obrigatórios, referentes a vida útil de projeto (NBR 15575). O valor da energia consumida pelos equipamentos é a que mais contribui para valor elevado da energia operacional na fase de uso.

A figura 6 apresenta os percentuais de consumo energético nas fases pré-uso, uso e pós-uso. A fase de uso aparece em primeiro lugar, com o maior valor, corresponde a $69 \%$ de energia operacional (EO). A fase de pré-uso, com $28 \%$, também apresenta parcela significativa do ciclo de vida. Vale destacar que a energia incorporada aos materiais na fase pré-uso precisa de estudos mais abrangentes, devido ao uso de dados nacionais e não regionais.

Figura 6: Percentuais de consumo energético nas fases pré-uso, uso e pós-uso em 50 anos. 


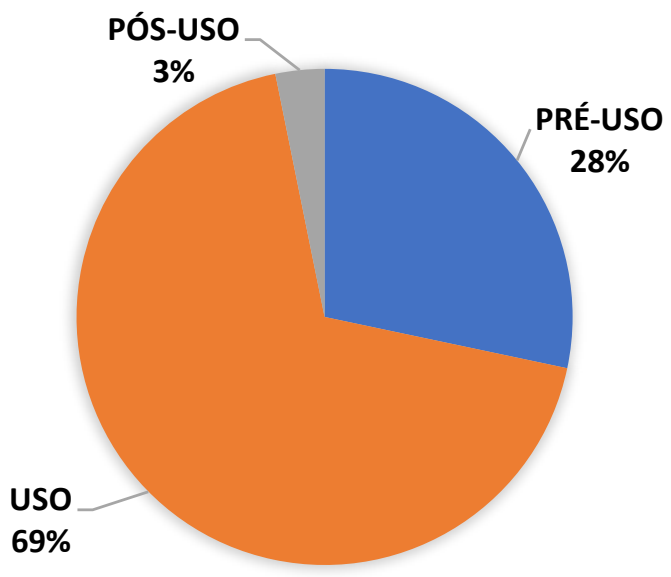

Fonte: Elaboração própria, 2020

A tabela 6 apresenta o detalhamento das energias dos principais material, selecionados para pesquisa do cenário existente para 50 anos, em $\mathrm{MJ}$ e $\mathrm{GJ} / \mathrm{m}^{2}$, e os respectivos percentuais para as energias que compõem cada fase conforme figura 7. Analisando a tabela 6 e figura 7 , temos em destaque na fase de pré-uso a energia de transporte de materiais, com $22 \%$, sendo o piso responsável pelo maior impacto nessa etapa.

Tabela 6: Energias por fases ciclo de vida energético dos principais materiais no cenário existente.

\section{FASES DO CICLO DE VIDA}

PRÉ-USO

ENERGIA

\begin{tabular}{|c|c|c|c|c|c|c|c|c|}
\hline \multicolumn{2}{|c|}{ EDIFICAÇÃO } & \multirow{2}{*}{$\begin{array}{c}\text { MATERIAL } \\
\text { EEmat }\end{array}$} & \multirow{2}{*}{$\begin{array}{l}\text { TRANSP. } \\
\text { MAT. } \\
\text { Etr.mat }\end{array}$} & \multirow{2}{*}{$\begin{array}{c}\text { DESPERDÍcIO } \\
\text { Edesp }\end{array}$} & \multirow{2}{*}{$\begin{array}{l}\text { TRANP. } \\
\text { DESP. } \\
\text { Etr.desp }\end{array}$} & \multirow{2}{*}{$\begin{array}{c}\text { MANUTENÇÃO } \\
\text { Eman }\end{array}$} & \multirow{2}{*}{$\begin{array}{c}\text { DEMOLIÇÃo } \\
\text { Edem }\end{array}$} & \multirow{2}{*}{$\begin{array}{l}\text { TRANSP. } \\
\text { DEM. } \\
\text { Etr.dem }\end{array}$} \\
\hline Sist. & Material & & & & & & & \\
\hline \multirow{4}{*}{ 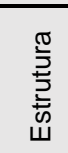 } & Cimento & $38,010.00$ & $243,535.50$ & $15,204.00$ & $26,494.78$ & 0.00 & 0.00 & 0.00 \\
\hline & Seixo & $2,931.75$ & $498,006.60$ & $1,172.70$ & $57,219.94$ & 0.00 & 0.00 & 0.00 \\
\hline & Areia & $1,465.50$ & $746,818.80$ & 732.75 & $107,259.95$ & 0.00 & 0.00 & 0.00 \\
\hline & Aço & $93,144.00$ & $224,818.57$ & $9,314.40$ & $2,272.40$ & 0.00 & 0.00 & 0.00 \\
\hline \multirow{5}{*}{$\begin{array}{l}\text { D } \\
\frac{1}{0} \\
\frac{d}{\sigma} \\
\frac{1}{0}\end{array}$} & $\begin{array}{l}\text { Bloco } \\
\text { cerâmico }\end{array}$ & $106,774.43$ & $96,686.09$ & $16,016.16$ & $40,421.49$ & $59,921.86$ & 325.85 & $67,369.14$ \\
\hline & Areia & 66.90 & $34,092.24$ & 29.44 & $4,308.84$ & $103,577.54$ & 134.99 & $27,909.54$ \\
\hline & Cimento & $30,870.00$ & $197,788.50$ & $29,326.50$ & $51,104.92$ & $808,081.76$ & 741.54 & $153,314.75$ \\
\hline & Tinta Acrílica & $6,658.15$ & $28,974.96$ & 998.72 & 119.83 & $192,631.67$ & 7.26 & $1,501.64$ \\
\hline & $\begin{array}{l}\text { Tinta PVA } \\
\text { látex }\end{array}$ & $12,567.10$ & $51,324.04$ & $1,885.07$ & 212.26 & $65,882.33$ & 1.38 & 286.03 \\
\hline \multirow{3}{*}{$\begin{array}{l}\frac{\pi}{J} \\
\stackrel{t}{0} \\
\frac{0}{0} \\
0\end{array}$} & Est. madeira & $6,115.20$ & $5,087.85$ & 917.28 & $13,427.14$ & $12,618.71$ & 290.08 & $59,974.58$ \\
\hline & Telha & $52,758.43$ & $187,976.34$ & $5,275.84$ & $7,150.72$ & $167,222.60$ & 231.73 & $47,909.83$ \\
\hline & Forro PVC & $20,160.00$ & 317.77 & $4,032.00$ & 368.88 & $16,545.12$ & 5.98 & $1,235.74$ \\
\hline \multirow{2}{*}{ Piso } & Porcelanato & $38,037.87$ & $780,537.09$ & $5,705.68$ & $3,212.30$ & \begin{tabular}{|l|}
$2,353,777.36$ \\
\end{tabular} & 295.20 & $61,033.66$ \\
\hline & Argamassa & $2,275.77$ & $6,128.32$ & 409.64 & $1,427.69$ & $27,153.59$ & 109.33 & $22,605.06$ \\
\hline \multirow{3}{*}{ 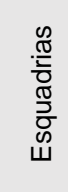 } & Madeira & $4,012.43$ & 194.74 & 601.86 & 587.34 & $18,192.25$ & 28.41 & $5,873.39$ \\
\hline & Alumínio & $19,983.60$ & $35,652.65$ & 0.00 & 0.00 & $37,276.28$ & 2.26 & 466.64 \\
\hline & Vidro & $1,685.35$ & $34,131.53$ & 0.00 & 0.00 & $23,997.31$ & 2.16 & 446.73 \\
\hline \multicolumn{2}{|c|}{ TOTAL MJ } & $437,516.48$ & $3,172,071.57$ & $91,622.04$ & $315,588.47$ & $3,886,878.39$ & $2,176.17$ & $449,926.74$ \\
\hline \multicolumn{2}{|c|}{ TOTAL GJ/m² } & 1.94 & 14.03 & 0.40 & 1.40 & 17.20 & 0.01 & 1.99 \\
\hline
\end{tabular}

Fonte: Elaboração própria, 2020 
Figura 7: Percentuais totais das energias em 50 anos nas fases pré-uso, uso e pós uso.

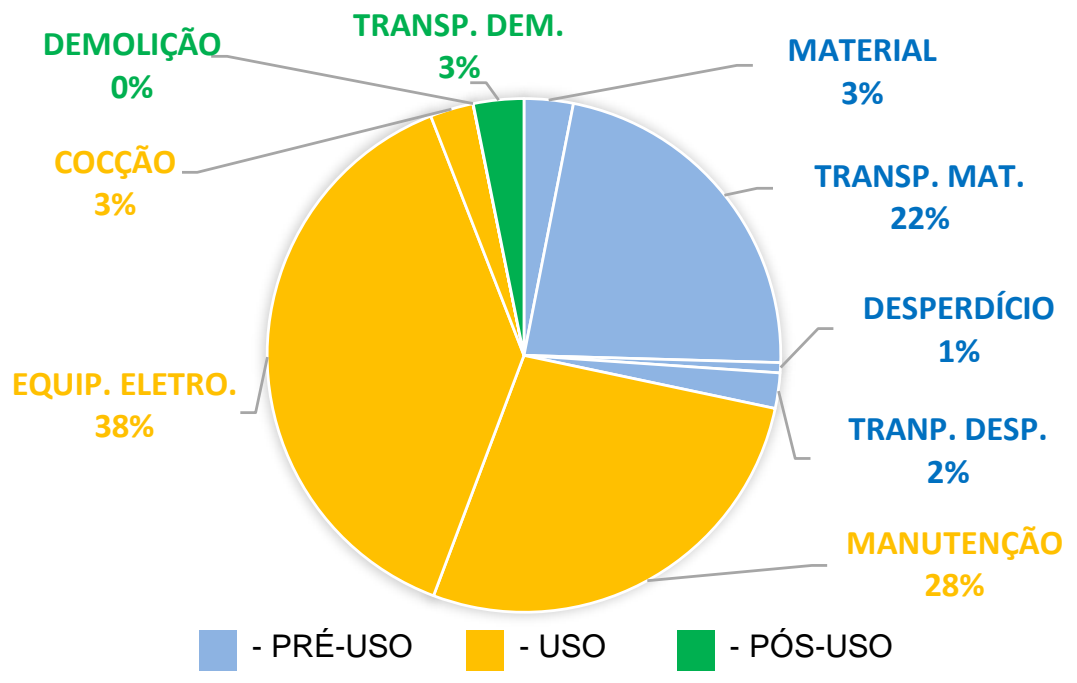

Fonte: Elaboração própria, 2020

$\mathrm{Na}$ fase de uso, a energia de equipamentos eletrodomésticos representa $38 \%$ do consumo de energia, seguida da energia de manutenção com $28 \%$, destacando o piso. Na fase pós-uso o maior percentual corresponde ao transporte de demolição com $3 \%$, sendo o cimento do sistema paredes responsável pelo maior impacto.

Outras análises foram realizadas para cada fase estudada. Assim, na fase de pré-uso, foi analisada a relação entre a massa dos sistemas estudados e a energia incorporada inicial (EII) de cada sistema e, a energia de transporte dos materiais da fábrica (Etr.mat) ao canteiro de obra. Na figura 8 os resultados apresentados, destaca o sistema de estrutura com maior participação em massa, consequentemente a Ell se destaca com alto percentual. Em seguida o sistema de paredes segue com elevado percentual de massa e energia, seguindo os padrões de estudos anteriores. Portanto, do ponto de vista do consumo de energia, o sistema de estrutura é o mais crítico, correspondendo a $51 \%$ da energia incorporada (EII).

Figura 8: Relação entre Massa dos sistemas e Energia Incorporada Inicial (a esquerda), e Massa e Energia de Transporte (a direita).

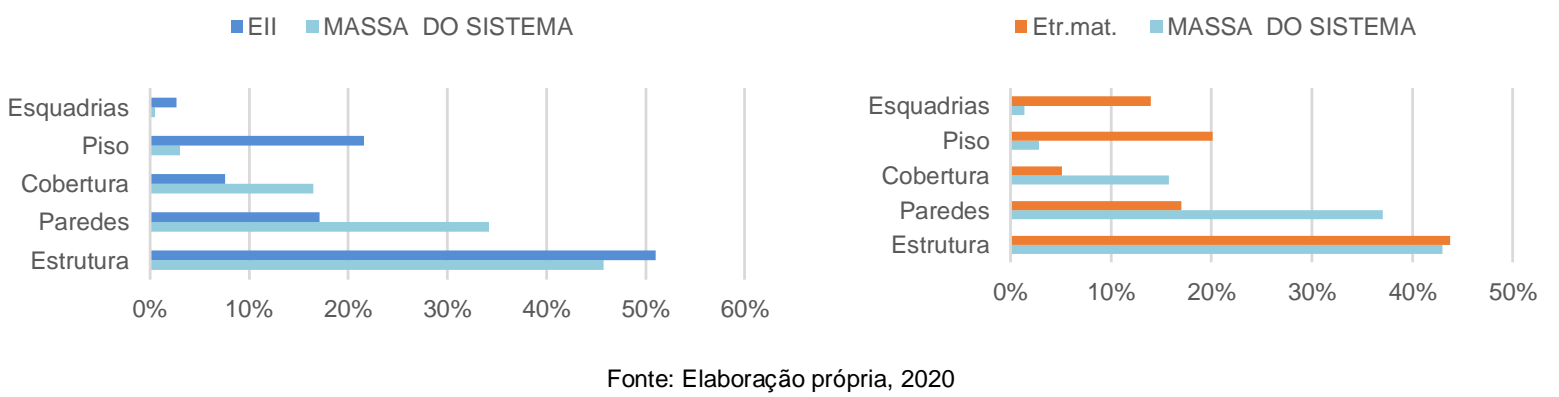

A energia associada a distância percorrida pelos materiais, destaca os sistemas de estrutura, piso e esquadrias, no caso das esquadrias, as de alumínio. Os sistemas de piso e esquadrias apresentam energia de transporte elevada, apesar da massa desses sistemas serem menores que o sistema de cobertura, por exemplo. Isto ocorre devido a variável de distância da fábrica ao canteiro de obra pois, 
nas duas situações, as fábricas estão fora da região Norte. O piso veio da região Nordeste e a esquadria de alumínio da região Sudeste.

Por outro lado, a estrutura apresenta elevada energia de transporte por possuir a maior massa dentre os sistemas e, dentre os componentes desse sistema, o aço apresenta a maior distância de transporte, $557 \mathrm{Km}$ (Google Maps) da fábrica ao canteiro de obra, contribuindo para o elevado percentual de aproximadamente $43 \%$ de energia de transporte.

A figura 9 apresenta a relação da energia incorporada nos componentes construtivos, nas fases préuso e uso. A comparação está nas etapas 1 e 2 (tabela 5), referente a energia incorporada inicial (EII), e etapa 7 (tabela 5) com a energia de manutenção (Eman) em GJ/Kg. Em destaque temos o piso e a tinta acrílica na energia de manutenção, esses valores estão associados ao fator de reposição e vida útil de projeto (VUP), correspondendo ao mínimo obrigatório, sugerida pelo guia da ASBEA, baseado nos dados da ABNT NBR 15575-1. Assim, ao longo dos 50 anos de vida útil, haverá aproximadamente 4 trocas de piso e 6 repinturas externas. Associado a isso, a energia incorporada da tinta externa e $61 \mathrm{MJ} / \mathrm{Kg}$, contribuindo para esse resultado.

Percebe-se que uma das influências nesses resultados está relacionada a durabilidade e vida útil dos materiais especificados. Com a diminuição da necessidade de reposição, levando em consideração as medidas previstas na NBR 15.575 (2013), há potencial redução da energia de manutenção.

Figura 9: Comparação da energia incorporada nas fases pré-uso e uso.

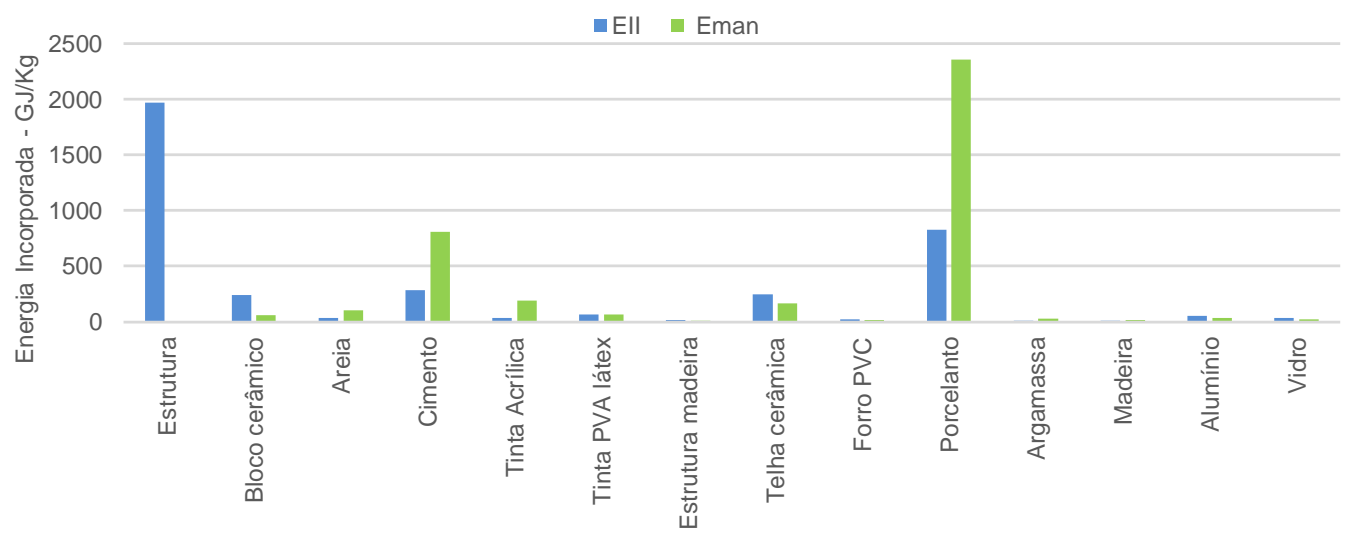

Fonte: Elaboração própria, 2020

Por conseguinte, a estrutura e o piso apresentam valores elevados na energia incorporada inicial. A estrutura por apresentar em seu sistema diversos materiais, logo maior massa justifica-se a elevada energia e o piso, por sua vez, possui elevada energia incorporada inicial em função da distância da fábrica.

$\mathrm{Na}$ fase de uso, o consumo de energia da edificação, no cenário proposto (cenário 1), apresentou um percentual de $55 \%$, que corresponde a um aumento de $17 \%$ sobre o cenário atual. Temos na figura 10 a relação entre o consumo médio, consumo anual e em 50 anos por $\mathrm{Kw} / \mathrm{h}$, para o cenário 1 , referência de maior consumo. Observa-se que nesse cenário, o sistema de ar-condicionado, mesmo com classificação A pela ENCE, apresentou maior consumo, seguido das lâmpadas compactas e geladeira.

Figura 10: Relação entre o consumo médio mensal, anual e para 50 anos do cenário 1 - proposto. 


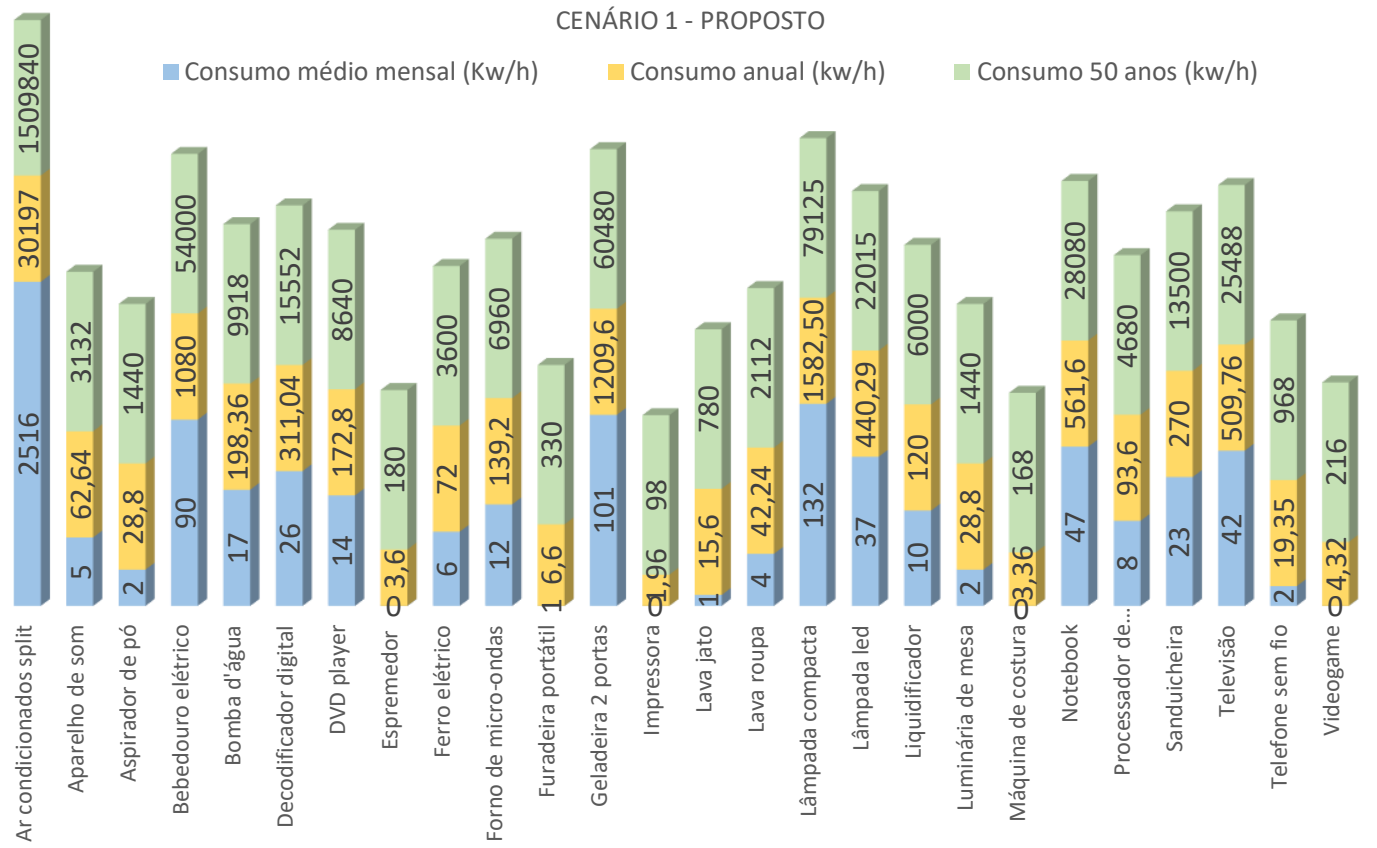

Fonte: Elaboração própria, 2020

Para o cenário 2, situação existente, a figura 11 apresenta o maior consumo das lâmpadas compactas, seguido dos ventiladores e geladeira. Em 50 anos os equipamentos elétricos correspondem a $77 \%$ de todo consumo de energia, seguido da iluminação com $23 \%$.

Figura 11: Relação entre o consumo médio mensal, anual e para 50 anos do cenário 2 - existente. CENÁRIO 2 - EXISTENTE

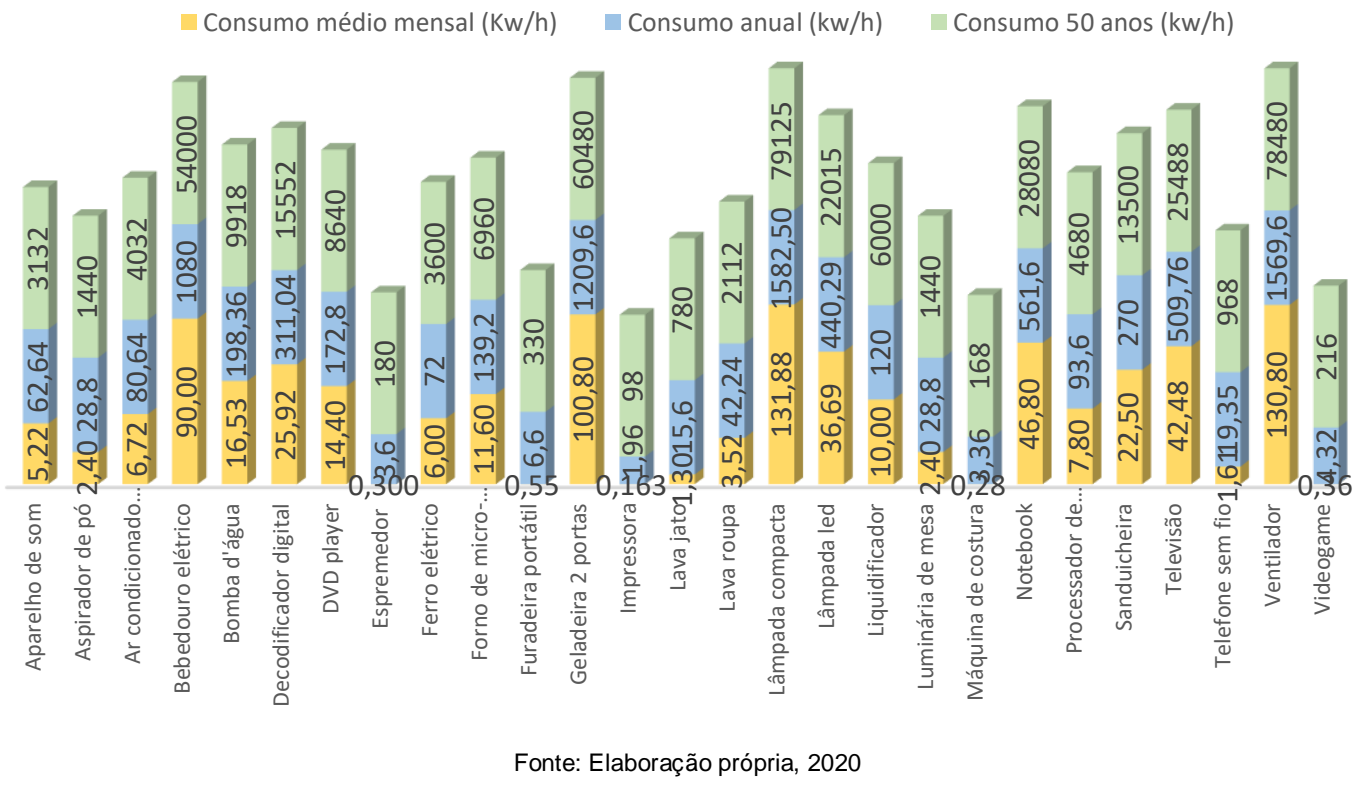

$\mathrm{Na}$ figura 12 temos os percentuais dos equipamentos considerados mais usuais em residência, esses percentuais são anuais para o cenário 2 (existente), destacando as lâmpadas com o maior consumo $36 \%$, seguindo dos ventiladores $28 \%$ e geladeira $22 \%$.

Figura 12: Relação do consumo dos equipamentos mais usuais em residência para cenário 4. 


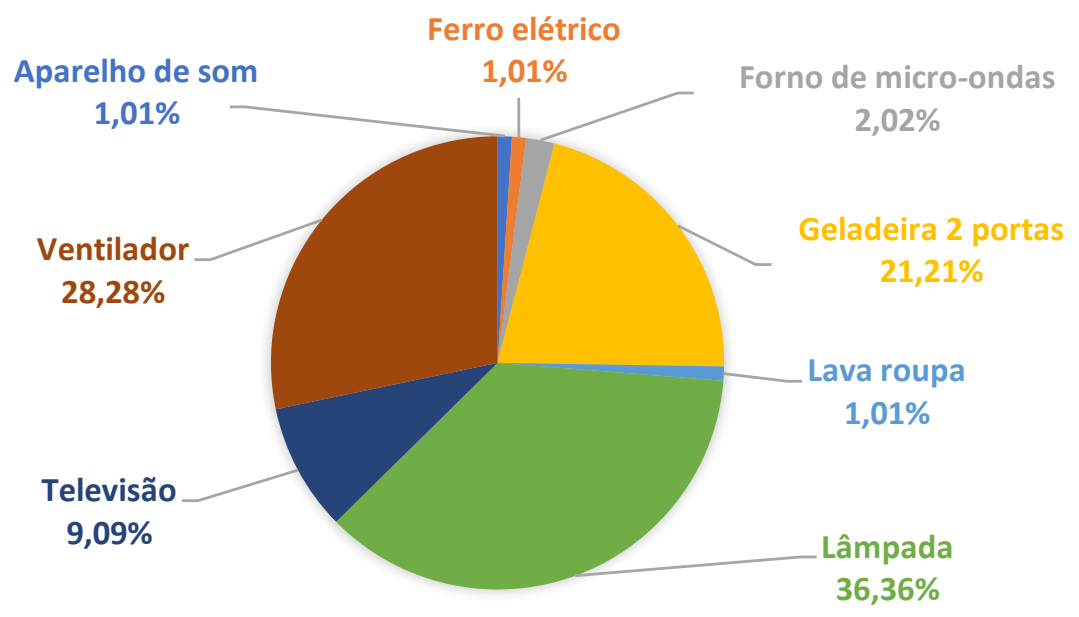

Fonte: Elaboração própria, 2020

Assim, o consumo médio anual de 8.628,27 Kwh, pode ser reduzido de duas formas para o bom rendimento e economia de energia: com ou sem intervenções físicas na residência. Sem intervenções, pode ser adotado a mudança de hábitos, por exemplo a troca das lâmpadas compactas por led, os ventilados podem ser trocados por aparelhos etiquetados mais eficientes.

As intervenções físicas são na envoltória da residência, como a pintura com cores claras, aliada na absorção e reflexão de calor e radiação de solar. A utilização de mantas térmicas para o isolamento da cobertura, junto com a camada de ar entre a cobertura e o forro, permite que as trocas de calor entre 0 meio externo e interno ocorram de forma gradual, evitando que o ambiente fique desagradável. A instalação de placas fotovoltaicas na cobertura para redução da conta de energia, além de ser uma alternativa sustentável.

Com relação a energia na fase de pós-uso, diversos estudos mostram a inexpressividade desse consumo energético em relação ao consumo total no ACVE: $3,5 \%$ no trabalho de Paulsen e Sposto (2013); 3,3\% para Silvia (2012). Na presente pesquisa apenas 3,0\%, confirmando o fato de ser não relevante (figura 6 ).

A pesquisa se propôs a classificar os dados necessários para realização do cálculo de ACVE em Belém do Pará, em: facilmente obtidos; demandam certo empenho e estudos abrangentes. Na tabela 7 temos a classificação distribuída entre distância, levantamentos e dados. O critério adotado está relacionado a forma de obtenção dos dados necessários para realização do cálculo dos consumos energéticos voltado para região de Belém do Pará.

Tabela 7: Classificação para obtenção dos dados para cálculo de ACVE.

\begin{tabular}{|c|c|c|}
\hline \multicolumn{3}{|c|}{ ACVE INVENTÁRIO LOCAL - Belém-Pa } \\
\hline FACILMENTE OBTIDOS & DEMANDAM CERTO EMPENHO & ESTUDOS ABRANGENTES \\
\hline $\begin{array}{l}\text { Distâncias: } \\
\text { - Transporte dos materiais; } \\
\text { - Transporte de desperdício; } \\
\text { - Transporte de demolição. } \\
\text { Dados: } \\
\text { - Fator de reposição; } \\
\text { - Fator de desperdício; } \\
\text { - Vida útil de projeto (VUP). }\end{array}$ & $\begin{array}{l}\text { Levantamento: } \\
\text { - Quantitativo de todo material } \\
\text { construtivo em Kg, quando não existe } \\
\text { projeto; } \\
\text { - Equipamento elétricos com potências } \\
\text { e horas de uso; } \\
\text { - Lâmpadas com potências e horas }\end{array}$ & $\begin{array}{l}\text { Dados: } \\
\text { - Energia incorporada de } \\
\text { materiais, com valores } \\
\text { para Região Norte: } \\
\text { cimento, seixo, areia, } \\
\text { aço, madeira, forro PVC } \\
\text { telha e bloco cerâmico. }\end{array}$ \\
\hline
\end{tabular}


de uso.

Fonte: Elaboração própria, 2020

Assim temos que a obtenção dos dados para inventário local está classificado como facilmente obtidos, para as distâncias, pois podem ser calculadas pelo Google Maps. Os dados como fator de reposição, podem ser encontrados na literatura técnica, o fator de desperdício e obtido pelo calculado do valor da vida útil (VUP), valor encontrado na NBR 15575-1, dividido pela vida útil adotado, sendo o mínimo obrigatório 50 anos.

Os dados que demandam certo empenho, estão relacionados aos levantamentos, que podem ser de dados de projeto ou "in loco", como o levantamento de todos os equipamentos que demandam consumo de energia. Os estudos abrangentes estão relacionados a dados que precisam de pesquisas como dissertações de Mestrado ou Doutorado, para se obter o valor da energia incorporada. Então, fazendo uma relação com a tabela 1 , temos que $70 \%$ dos dados são facilmente obtidos, $10 \%$ demandam certo empenho e $20 \%$ precisam de estudos abrangentes.

\section{Conclusão}

A pesquisa realizou a quantificação da energia incorporada total ao longo do ciclo de vida de 50 anos de uma residência localizada em Belém do Pará, nas etapas de pré-uso, uso e pós-uso, com escopo de berço ao túmulo. Além de identificar os potenciais de economia energética e classificar os dados obtidos para a metodologia completa de Análises de Ciclo de Vida Energético em estudos de edificações.

A principal contribuição desse trabalho foi poder aplicar a metodologia de ACVE em uma edificação existente, realizando uma análise do consumo energético ao logo de todo ciclo de vida, tipo de estudo com carência no país. Foi verificado que para o cenário 2 (existente) o valor de energia incorporada total corresponde a $62.75 \mathrm{GJ} / \mathrm{m}^{2}$. A falta de pesquisas em ACVE no país, em residências existentes, aliada a adaptação das informações dos dados do inventário, não permitiu a comparação do valor apresentado. $O$ fato de os dados terem sido obtidos de forma secundária, para itens como consumo energético de transporte e a energia incorporada inicial do seixo, ter sido adotado valor da brita, sugere que os resultados devam ser analisados com cautela e de forma híbrida.

Outra contribuição foi classificar os dados obtidos para realização da metodologia, concluindo-se que $20 \%$ dos dados demandam estudos abrangentes, refletindo a dificuldade em aplicar a metodologia com dados de inventários locais, o que se reflete a falta de homogeneidade metodológica na aplicação da ferramenta.

Relacionadas a fase de pré-uso, as energias de prospecção, transporte e fabricação de materiais e componentes são significativas, correspondendo a $28 \%$ do total de energia consumida pela residência. No entanto, a energia operacional na fase de uso, apresentou o maior impacto energético de $69 \%$, devido a extensão do período avaliado, 50 anos.

A energia de transporte nas fases de pré-uso e pós-uso, merece a atenção, pois a distância influência na energia incorporada total. Assim, se todos os materiais utilizados na construção fossem de fabricas da região, o valor referente a energia de transporte seria bem menor.

Outro ponto importante está relacionado a especificação de materiais com maior durabilidade. Nesse sentido, atender ao mínimo obrigatório da NBR 15.575, pode refletir um impacto energético no fator de reposição dos materiais. Isso ocorre devido ao número de reposições dos materiais ao longo da vida útil da edificação. Por exemplo, o piso seguindo a norma de desempenho com VUP mínimo obrigatório $(\geq 13)$, terá um fator de reposição igual a 3,84 , isso reflete em aproximadamente 4 manutenções ao longo de 50 anos. Para o VUP superior $(\geq 20)$, o fator de reposição será 2,5 , assim, ocorrerá 
aproximadamente 2 manutenções no piso. Portanto, a durabilidade dos materiais influencia no valor da energia de manutenção, que somada a energia de consumo dos equipamentos elétricos eleva o valor da energia operacional na fase de uso.

O sistema estrutural apresenta a maior participação em massa, com aproximadamente $43 \%$, enquanto as esquadrias o menor, com aproximadamente $0,54 \%$. Assim, temos que o sistema estrutural possui maior energia incorporada inicial com 51\%. O sistema parede apresentou maior energia de manutenção em função das tintas e maior energia de demolição.

Por fim, recomenda-se o estudo mais abrangente para obtenção da energia incorporada inicial do seixo, aglomerado amplamente utilizado na região norte, para compor sistemas construtivos. Isso vale também para os seguintes materiais: cimento, areia, aço, madeira, forro PCV, telha e blocos cerâmicos, que fazem parte do sistema construtivo básico de residências, e possuem fábricas na região norte. Com os dados de energia incorporada para esses materiais, o cálculo do consumo energético total ficará mais próximo da realidade. A partir desses dados de consumo inventariados, surge a oportunidade para o desenvolvimento de políticas públicas na região, voltadas a reduzir os impactos ambientais relacionados ao uso racional de energia.

\section{Referências Bibliográficas}

AGOPYAN, V.; SOUZA, U. E. L.; PALIARI, José Carlos; ANDRADE, A. C. Alternativas para a redução do desperdício de materiais nos canteiros de obras: relatório final. São Paulo: EPUSP/PCC, 1998. v. 5. Disponível em: <http://perdas.pcc.usp.br/Volume3/index.htm>. Acesso em: 20 jun. 2020.

ASSOCIAÇÃO BRASILEIRA DOS ESCRITÓRIOS DE ARQUITETURA - ASBEA. Guia para arquitetos na aplicação da norma de desempenho ABNT NBR 15.575. Disponível em: <http://www.asbea.org.br/manuais>. Acesso em: 12 junho. 2020.

ASSOCIAÇÃO BRASILEIRA DE NORMAS TÉCNICAS (ABNT). NBR 15.575. Edificações Habitacionais - Desempenho. Parte 1: Definições, símbolos e unidades. Rio de Janeiro, 2013.

NBR ISO 14.040: Gestão ambiental Avaliação do Ciclo de Vida - Princípios e estrutura. Associação Brasileira de Normas Técnicas (ABNT). Rio de Janeiro. 2009, Versão Corrigida: 2014a

BLOK, K.; NIEUWLAAR, E. Introduction to energy analysis. Second edition, London: Taylor and Francis, 2017.

BRASIL. Balanço Energético Nacional 2018: Relatório Síntese - Ano base 2017. Disponível em: $<$ https://ben.epe.gov.br>. Acesso em 15 maio. 2020.

CALDAS, Lucas; PEDROSO, Gilson; SPOSTO, Rosa Maria. Avaliação do Ciclo de Vida Energético (ACVE) de uma habitação. Arquitextos, São Paulo, ano 16, n. 191.06, Vitruvius, abr. 2016. Disponível em: <http://www.vitruvius.com.br/revistas/read/arquitextos/16.191/6012>. Acesso em: 10 maio. 2020.

CARVALO, T. N.; SILVOLO, M. M. A avaliação do ciclo de vida e a arquitetura: metodologia de ACV como ferramenta de decisão de projeto. In: IX ENCONTRO NACIONAL, VII ENCONTRO LATINOAMERICANO, II ENCONTRO LATINO-AMERICANO E EUROPEU SOBRE EDIFICAÇÕES SUSTENTÁVEIS, 2017, São Leopoldo. Anais... RS: Euro Elecs, 2017.

CTE; CRIATIVE. Sustentabilidade: Tendências na construção 2015. São Paulo: O Nome da Rosa, 2015.

EMPRESA DE PESQUISA ENERGÉTICA - EPE. Balanço Energético Nacional 2018 - Ano base 2017. Rio de Janeiro, 2017. 
EVANGELISTA, Patrícia; TORRES, Ednildo; GONÇALVES, Jardel. A Avaliação do Ciclo de Vida (ACV) como ferramenta de análise do desempenho ambiental de edificações. In: ENCONTRO NACIONAL DE TECNOLOGIA DO AMBIENTE CONSTRUÍDO, 16., 2016, São Paulo. Anais... Porto Alegre: ANTAC, 2016.

FAY, R.; TRELOAR, G.; IYER-RANIGA, U. Life-cycle energy analysis of buildings: a case study. Building Research and Information, 28 (1) p. 31-41 JAN-FEB. Routledge, London. 2000.

FREITAS, Ludmila de Souza; SCHMID, Aloísio Leoni; SILVA, Roberto Caldeira. A tomada de decisão na previsão da vida útil de projeto para edificações mais sustentáveis. In: ENCONTRO NACIONAL DE TECNOLOGIA DO AMBIENTE CONSTRUíDO, 16. 2016, São Paulo. Anais... Porto Alegre: ANTAC, 2016.

HEINONEN, J. et al. Pre-use phase $\{L C A\}$ of a multi-story residential building: $\{C a n\}$ greenhouse gas emissions be used as a more general environmental performance indicator? Building and Environment, v. 95, p. 116-125, 2016.

INSTITUTO NACIONAL DE METROLOGIA, QUALIDADE E TECNOLOGIA - INMETRO. Tabela de consumo/ eficiência energética. Disponível em: $<$ http://www.inmetro.gov.br/CONSUMIDOR/pbe/condicionadores.asp>. Acesso em: 08 de julho de 2020.

MORAGA, G.; CRUZ, I.; TORRES, M.; KIRCHHEIM, A.; PASSUELLO, A. Inventário de ciclo de vida energético de casa com paredes de concreto do programa minha casa minha visa. In: IX ENCONTRO NACIONAL, VII ENCONTRO LATINO-AMERICANO, II ENCONTRO LATINO-AMERICANO E EUROPEU SOBRE EDIFICAÇÕES SUSTENTÁVEIS, 2017, São Leopoldo. Anais... RS: Euro Elecs, 2017.

MADEIRA, J. G. da Silva. Avaliação do ciclo de vida energético e desempenho da envoltória mediante ações de retrofit em edificação pública escolar. 2019. 195 f. Dissertação (Mestrado) Universidade Federal do Espírito Santo, Vitória, 2019.

PAULSEN, J. S.; SPOSTO, R. M. A life cycle energy analysis of social housing in Brazil: Case Study for the program "MY HOUSE MY LIFE". Energy and Buildings. v.57. p. 95-102. 2013.

RAMESH, T.; PRAKASH, Ravi; SHUKLA, K.k. Life cycle energy analysis of buildings: An overview. Energy and Buildings, v. 42, n. 10, p.1592-1600, out. 2010. Elsevier BV.

SARTORI, I.; HESTNES, A. G. Energy use in the life cycle of conventional and low-energy buildings: A review article. Energy and Buildings, v. 39, n. 3, p. 249-257, mar. 2007.

SATTLER, Miguel Aloysio. Ecoconstruções. Apostila do curso de pós-graduação lato sensu em Reabilitação Ambiental Sustentável Arquitetônica e Urbanística - Reabilita 9. FAU - UNB. Brasília, 2019.

SILVA, Fernanda et al. Aspectos metodológicos para a realização de estudos de avaliação de ciclo de vida (ACV) para produtos de construção. In: ENCONTRO NACIONAL DE TECNOLOGIA DO AMBIENTE CONSTRUÍDO, 16., 2016, São Paulo. Anais... Porto Alegre: ANTAC, 2016.

SILVA, L. P. Análise do ciclo de vida energético de habitações de interesse social. 2012. 185 f. Dissertação (Mestrado em Engenharia Civil) - Programa de Pós-graduação em Engenharia, UFRGS, Porto Alegre, 2012.

SOCIEDADE FOGÁS LTDA. Conversão de $\mathbf{1 k g}$ de GLP para $\mathrm{KW} / \mathbf{h}$. Disponível em: 
https://www.fogas.com.br/granel/glp-gasnatural-energiaeletrica/. Acesso em: 19 agosto 2020.

SPOSTO, R. M.; PAULSEN, J. S Energia Incorporada em habitações de interesse social na fase de pré-uso: O caso do programa Minha Casa Minha Vida no Brasil. Revista Oculum Ensaios, Campinas, SP, págs. 39-50, janeiro-junho 2014.

TAVARES, Sérgio Fernando. Metodologia de análise do ciclo de vida energético de edificações residenciais brasileiras. 2006. 225 f. Tese (Doutorado) - Curso de Engenharia Civil, PPGEC, Universidade Federal de Santa Catarina, Florianópolis, 2006.

TEODORO, M. I. T. d. M. Energia embutida na construção de edificações no Brasil: Contribuições para o desenvolvimento de políticas públicas a partir de um estudo de caso em Mato Grosso do Sul. 2017. 234 f. Tese (Doutorado em Ciências) - Programa de Pós Graduação em Energia - Instituto de Energia, Universidade de São Paulo, 2017.

TOMÉ, Mauricio de Castro. Análise do impacto do chuveiro elétrico em redes de distribuição no contexto da tarifa horossazonal. 2014. [s.n.]. Dissertação (mestrado) - Universidade Estadual de Campinas, Faculdade de Engenharia Elétrica e de Computação, Campinas, SP. Disponível em: <http://www.repositorio.unicamp.br/handle/REPOSIP/259504>. Acesso em: 02 julho. 2020

YOKOO, N; YOKOYAMA. K. (Ed). Evaluation of Embodied Energy and CO2eq for Buildings Construction (Annex 57). Overview of Annex 57 Results. Japan: Institute for Building Environment and Energy Conservation, 2016.

\section{Simone de Fátima Campos Costa}

Arquiteta e Urbanista, discente no mestrado do Programa de Pós-Graduação em Arquitetura e Urbanismo - PPGAU 2020. Especialista em Reabilitação Ambiental Sustentável Arquitetônica e Urbanística, e Conforto Ambiental e Sustentabilidade do Espaço Construído e Eficiência Energética, consultora RTQ - C capacitada pela Quali- A, Master em Arquitetura (área de conhecimento Projeto de Arquitetura). Atuação profissional em vários projetos comerciais, residenciais e voluntários em Belém do Pará.

Contribuição de autoria: fundamentação teórico-conceitual e problematização; pesquisa de dados e análise estatística; elaboração de figuras e tabelas; elaboração e redação do texto; seleção das referências bibliográficas; revisão do texto.

\section{Darja Kos}

Natural de Ljubljana - Eslovênia. Mora no Brasil desde 1994. Arquiteta pela Faculdade de Arquitetura e Urbanismo da Universidade Presbiteriana Mackenzie de São Paulo (1999). Mestre em Arquitetura e Urbanismo pela Universidade de Brasília, na área de conforto ambiental (2005). Possui MBA em Construções Sustentáveis pela Universidade Cidade de São Paulo (UNICID). Desde 2007 atua como professora do Curso de Especialização em Reabilitação Sustentável Arquitetônica e Urbanística (Reabilita) ministrado pela FAU/UnB. Sócia-diretora da empresa Ambiente Eficiente Consultoria, desde 2011. Consultora capacitada pela Fundação Vanzolini no Processo AQUA-HQE (Haute Qualité Environnementale) e pelo LACAM/FAU/UnB no processo de etiquetagem de edifícios PROCEL/Inmetro. Credenciada LEED GA (Green Associate) pelo Green Building Council Institute (GBCl). Consultora GBC Brasil Casa pelo Green Building Council Brasil. Profissional HBC PRO pelo Healthy Building Certificate (HBC). Atua sobretudo nas áreas de eficiência energética, iluminação natural, conforto térmico e sustentabilidade nas edificações.

Contribuição de autoria: fundamentação teórico-conceitual e problematização, elaboração e redação do texto, revisão do texto artigo. 
Como citar: COSTA, Simone de Fátima Campos; KOS, Darja. Aplicação da Metodologia de Avaliação do Ciclo de Vida Energético a uma Residência em Belém-PA. Revista Paranoá. n.30, jan/jun 2021. DOI 10.18830/issn.1679-0944.n30.2021.04

Editores responsáveis: Caio Frederico e Silva e Daniel Richard Sant'Ana. 